\title{
The impact of tumour size on the probability of synchronous metastasis and survival in renal cell carcinoma patients: a population-based study
}

\author{
Johann P Ingimarsson ${ }^{1,4^{*}}$, Martin I Sigurdsson', Sverrir Hardarson², Vigdis Petursdottir², Eirikur Jonsson?', \\ Gudmundur V Einarsson ${ }^{1}$ and Tomas Gudbjartsson ${ }^{1,3}$
}

\begin{abstract}
Background: The observed low metastatic potential and favorable survival of small incidentally detected renal cell carcinomas (RCCs) have been a part of the rationale for recommending partial nephrectomy as a first treatment option and active surveillance in selected patients. We examined the relationship between tumor size and the odds of synchronous metastases (SMs) (primary outcome) and disease specific survival (secondary outcome) in a nationwide RCC registry.

Methods: Retrospective study of the 794 RCC patients diagnosed in Iceland between 1971 and 2005. Histological material and TNM staging were reviewed centrally. The presence of SM and survival were recorded. Cubic spline analysis was used to assess relationship between tumor size and probability of SM. Univariate and multivariate statistics were used to estimate prognostic factors for SM and survival.

Results: The probability of SM increased in a non-linear fashion with increasing tumor size $(11,25,35$, and 50\%) for patients with tumors of $\leq 4,4.1-7.0,7.1-10.0$, and $>10 \mathrm{~cm}$, respectively. On multivariate analysis, tumor size was an independent prognostic factor for disease-specific survival ( $H R=1.05,95 \% \mathrm{Cl} 1.02-1.09, p<0.001)$, but not for SM.

Conclusion: Tumor size affected the probability of disease-specific mortality but not SM, after correcting for TNM staging in multivariate analysis. This confirms the prognostic ability of the 2010 TNM staging system for renal cell cancer in the Icelandic population.
\end{abstract}

Keywords: Renal cell carcinoma, Size, Metastasis, Survival

\section{Background}

The ability to detect subclinical small renal cell carcinomas (RCCs) has greatly improved due to increased usage of abdominal imaging for unrelated disease [1]. This has altered the therapeutic approach to RCCs and over the past decade, nephron-sparing surgery (NSS) has replaced radical nephrectomy as the preffered treatment for RCCs less than $7 \mathrm{~cm}$ in size, when technically feasible, as suggested by both the European and American Guidelines $[2,3]$. These guidelines further recommend active surveillance or other minimally invasive treatments (i.e. radioablation or cryotherapy) as an alternative to surgery for

\footnotetext{
* Correspondence: johann.p.ingimarsson@hitchcock.org

'Departments of Urology and Surgery, Memphis, Tennessee, USA

${ }^{4}$ Dartmouth-Hitchcock Medical Center, Lebanon, New Hampshire, USA Full list of author information is available at the end of the article
}

patients with significant co-morbidities or advanced age. This is in part based on the assumption that the biological behaviour of smaller tumours is more benign than that of larger tumours, after observations of a low rate of metastasis and better survival of patients with smaller tumours [2-4].

The importance of knowing the exact size in prediction of outcome has been a matter of debate in the literature. While the study by Klatte et al., which focussed on tumours smaller than $4 \mathrm{~cm}$, did not find a significant relationship between tumor size and the probability of SM and survival, numerous other studies have supported such a correlation [5-11]. Several studies have evaluated various size cut-off points to improve prognostication, but there have been conflicting results [12]. The 2010 revision of the TNM system emphasized size by subdividing the T2 stage into T2a and T2b catergories at the 10-cm cut-off 
point, although subsequent publications have questioned any prognostic difference between the two new stages $[13,14]$.

Most studies that have investigated the relationship between size and SM have been based on data from single or multiple institutions. Importantly two population-based databases are available: the Surveillance, Epidemiology, and End-Results Database (SEER) and the National Swedish Kidney Cancer Quality Register (NSKCR) $[6,7,15,16]$. While covering larger populations, these databases did not offer a central review of staging or pathology, risking inter observer discrepancies with regards to stage and histology.

We therefore conducted a nationwide study using a centralized RCC database and a revised histological classification to test the relationship between RCC size and the probability of SM (primary outcome) and DSS (secondary outcome).

\section{Methods}

We conducted a retrospective nationwide study that included all patients diagnosed with RCC in Iceland between January 1, 1971 and December 31, 2005. The Icelandic Cancer Registry and centralized pathology and clinical registries of all hospitals in Iceland were cross-checked with the inclusion list, giving a 100\% match.

Clinical information was obtained from the medical records, including age, gender, symptoms, diagnostic work-up, and treatment. An incidental diagnosis was defined as tumours detected with imaging techniques or during surgery for reasons other than those related to clinical signs caused by renal tumours. In surgical cases, routine lymphadenectomy was not performed, but enlarged lymph nodes were usually removed. Postoperative follow-up was performed at each hospital or at outpatient clinics for the first 1-2 years. Follow-up thereafter for recurrence was per physician preference and not standardized. A chest X-ray was performed in all patients preoperatively, together with a computed tomography (CT) and/or ultrasound (US) of the liver when these tests became available. CT scans of the chest, brain, bone scans, magnetic resonance imaging (MRI), or cavography were performed selectively. PET scan was not available in Iceland during the study period.

Two of the authors, both consulting pathologists (S.H. and V.P), reviewed haematoxylin and eosin-stained slides, using accepted criteria by WHO and the Heidelberg classification for stratifying the histological subtypes [17]. The following pathology findings were recorded: Fuhrman nuclear four-grade scale, lymph node status, invasion of vessels, adrenals, and Gerotas fascia. As imaging modalities varied during the study period, tumour size was determined from the pathology specimens as the greatest diameter in $\mathrm{mm}$. In the non-surgically treated cases, size, as measured by radiologists from CT scans, US, or intravenous pyelograms, was used. The spread of tumours was assessed using the most recent version of the TNM classification system and with stage grouping (I-IV) as proposed by AJCC $[17,18]$. Synchronous metastases were defined as metastases present at or within three months of the diagnosis of the primary kidney tumour.

All the patients were followed up for survival by using data from the updated National Population Registry, and they were assigned a date and cause of death (as registered on the death certificate) or identified as living on 31 December 2009. Median follow-up of survival was 4.5 years (range $0-34$ years), and none of the patients were lost to follow-up.

Chi-square test and Mann-Whitney U test were used to compare univariate proportions and means, respectively. A p-value of $<0.05$ was considered to be statistically significant. To graphically demonstrate a relationship between tumour size and probability of SM, we used cubic spline analysis-which makes no assumption about the relationship between parameters and is entirely data-driven. Independent prognostic factors for the presence of SM were assessed with logistic regression. The model included all univariate variables with $\mathrm{p}<0.1$. This included age, gender, calender year of diagnosis, tumor size, incidental diagnosis, histological subtype, laterality, estimated sedimentation rate (ESR) and pT stage. Since pT stage is highly dependant on size, analysis for SM were performed both with and without pT stage.

Cox proportional hazards analysis was used to determine independend predictors of and disease-specific survival (DSS). Cox proportional hazards analysis was used to determine independend predictors of disease-specific survival (DSS), using data from all patients with sufficient histology and staging data $(\mathrm{n}=794)$. The model included all univariate variables with a $p$-value of $<0.1$, including size, group TNM-stage and Fuhrman grade, ESR levels, incidental diagnosis, and calendar year of diagnosis. In the multivariate analysis for SMs, the pT stage rather than the TNM group stage was used, since the presence of metastases was included in the TNM group subset. Size was considered a continuous variable in all multivariate analysis.The statistical software package $\mathrm{R}$, version 2.10.1, was used for all analyses (the R Foundation, Vienna, Austria).

This study was approved by the National Bioethics Committee and the Icelandic Data Protection Agency. As individual patients were not identified, individual consent for the study was waived.

\section{Results}

Altogether, 913 patients were diagnosed with RCC during the 35 year study period, but 116 patients were excluded; 65 because detailed information on tumor size was lacking 
and 51 cases that only were clinically diagnosed as RCC (histology missing). This left 794 with histopathologically confirmed disease that were used for calculations. Nephrectomy was performed in 702 out of 794 cases $(4.1 \%$ of them partial) with 92 patients being treated non-surgically. No patients were treated with cryothearpy or radioablation, as these techniques were only available after 2006 in Iceland.

Patient demographics and treatment are shown in Table 1. The ratio of males to females was 1.5, the average age was 65 years, and $29 \%$ of the tumors were detected incidentally.

\section{Size and synchronous metastases}

Mean tumor size was $7.2 \pm 3.8 \mathrm{~cm}$ (median 6.7, range 0.330.0). Tumors diagnosed in the first 5 years were larger $(8.4 \mathrm{~cm})$ than those diagnosed in the last 5 years $(6.5 \mathrm{~cm})$ ( $\mathrm{p}<0.01$ for trend). The proportion of patients with confirmed p T stages 1, 2, 3, and 4 were $35 \%, 17 \%, 39 \%$, and $4 \%$, respectively. Altogether, 247 patients (30\%) were diagnosed with SMs, with lungs $(n=121)$, bones $(n=80)$, and liver $(n=51)$ being the most common metastatic sites.

When pathologically confirmed tumors were classified into $1-\mathrm{cm}$ size categories, there was a positive correlation between increasing size and the probability of SM (Figure 1) $\left(\mathrm{R}^{2}=0.80, \mathrm{p}<0.0001\right)$. This correlation was retained in a sub analysis of localized tumors (pT1 and pT2) $\left(\mathrm{R}^{2}=0.83, \mathrm{p}<0.0001\right)$, but not when the pT3 or pT4 tumors were analyzed $\left(R^{2}=0.58, p=0.12\right)$. Figure 2 shows a cubic spline analysis of the relationship between size and the probability of SM.

Table 2 shows a comparison of patients with and without SM. Patients with SM had significantly larger tumors (mean 9.0 vs. $6.5 \mathrm{~cm})(\mathrm{p}<0.001)$, higher T stage, higher Fuhrman grade, higher ESR, and earlier calendar year of diagnosis. Furthermore, they were less frequently diagnosed incidentally and more often had tumor in the left kidney. There were, however, no significant differences in gender, age, or histological subtype. The proportion of SM for tumours less than $4.0 \mathrm{~cm}$ was $11 \%$ (20/188), but $7 \%$ when only tumors detected after 1990 were included ( $90 \%$ of them being diagnosed incidentally).

\section{Table 1 Patient characteristics}

\begin{tabular}{|c|c|}
\hline Average age (range) & $64.0 \pm 12.9(17-93)$ \\
\hline Male: female ratio & 1.6 \\
\hline Right kidney, n (\%) & $413(59)$ \\
\hline Incidental detection, n (\%) & $150(21)$ \\
\hline \multicolumn{2}{|l|}{ First treatment } \\
\hline Radical nephrectomy, n (\%) & $673(84)$ \\
\hline Partial nephrectomy, n (\%) & $29(4)$ \\
\hline Non surgical on no treatment, n (\%) & $92(12)$ \\
\hline
\end{tabular}

A multivariate logistic regression analysis revealed that symptomatic diagnosis, elevated ESR, left kidney tumor and a size increment of $1 \mathrm{~cm}$ were independent prognostic factors for SM (Table 3). In a model including tumor stages, size was not retained as an independent prognostic factor. However, symptomatic presentation, elevated ESR and left kidney tumor continued to be independent prognostic factors. When included, higher tumour stage was the strongest predictor in all models.

\section{Size and survival}

There was significantly better survival in patients with smaller tumors $(\mathrm{p}<0.001, \log$ rank test). DSS at 5 years was $86 \%$ for tumors of $<4 \mathrm{~cm}, 72 \%$ for tumors between 4 and $7 \mathrm{~cm}, 53 \%$ for tumors between 7 and $11 \mathrm{~cm}$, and $32 \%$ for tumors larger than $11 \mathrm{~cm}$.

In a univariate analysis, less favorable DSS was related to the following factors: increasing tumor size, higher group stage and Fuhrman grade, high ESR levels, presentation with symptoms, and year of diagnosis. In the Cox analysis shown in Table 4, TNM group stage, Fuhrman nuclear grade, calendar year of diagnosis, and incidental detection were still independent predictors of DSS. Size remained a statistically significant albeit small predictor $(\mathrm{HR}=1.05$, CI 1.02-1.09, $\mathrm{p}<0.001)$ when TNM group stage was added to the multivariate model.

A subcategory of patients with histopathologically confirmed and organ confined (T1/T2,N0,M0) RCC (without synchronous metastasis) underwent nephrectomy $(n=370) ; 6 \%$ of them with partial nephrectomy. Sixty four of the 370 patients (17.4\%) ultimately died from RCC, 5-371 (mean 100, medial 70) months after surgery. Patient characteristics and univariate analysis are shown in Table 5. A multivariate logistic regression analysis revealed that only year of diagnosis (OR 0.93 for each calendar year), elevated ESR (OR 1.01 per $1 \mathrm{~mm} /$ hour) and a size (OR 1.21 per one $\mathrm{cm}$ increment, 95\% CI 1.03-1.58, $\mathrm{p}=0.02$ ) were independent prognostic factors for DSS in this subcategory of patients. If the multivariate model also included tumor stage, size fell short of being retained as an independent prognostic factor (OR 1.17, 95\% CI 0.99-1.39, p = 0.053).

\section{Discussion}

Our results show that increasing size of RCC tumours is associated with a higher probability of SM and worse survival in an unselected nationwide RCC registry. Tumour size remained an independant predictive factor for DSS after multiple corrections, albeit with a limited additional prognostic value when the TNM group stage was added to the model. While tumor size did predict SM in multivariate analysis, it did not independently predict the probability of SM when the T stage was added to the model. 


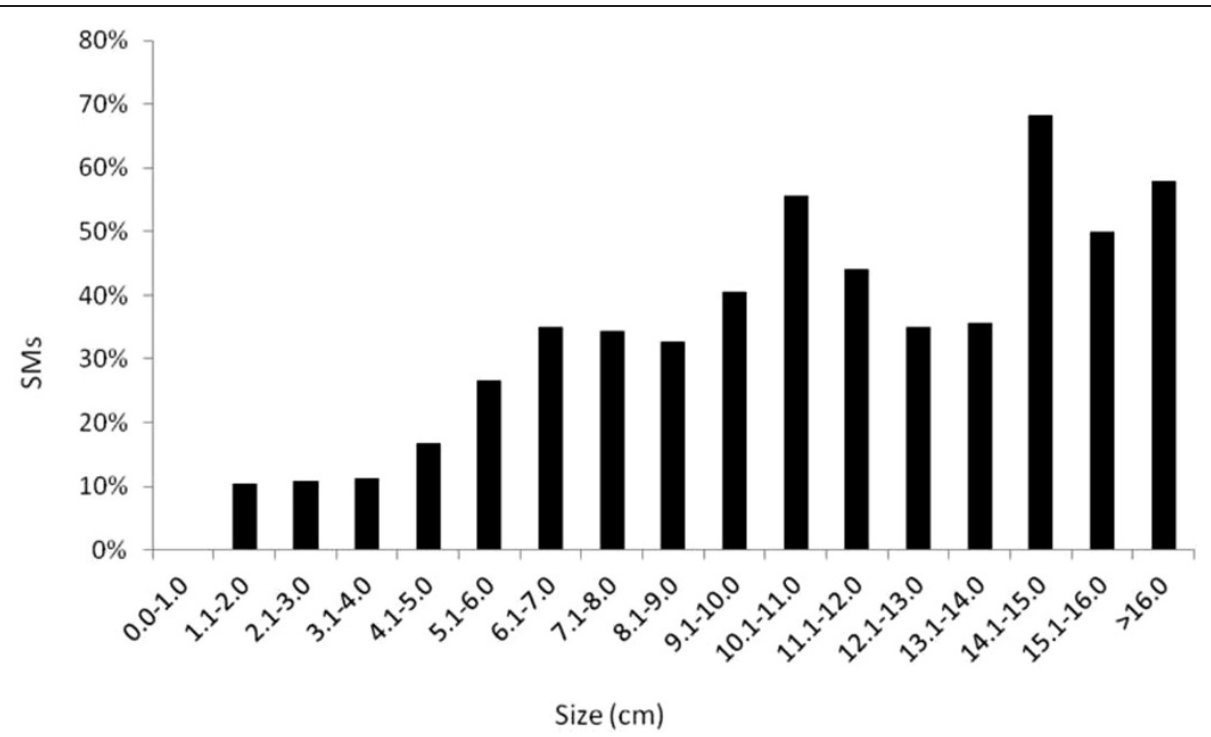

Figure 1 Proportion of synchronous metastases as stratified by $1-\mathbf{c m}$ tumor size intervals. Tumors above $16 \mathrm{~cm}(\mathrm{n}=18)$ have been pooled, as there were less than 2 cases in each $1-\mathrm{cm}$ category.

Our results add to the findings from studies using the SEER and the NSKCR databases, which were also population based patient cohorts $[6,7,15]$. The strength of our study is that the data include all patients diagnosed in a whole country over a 35-year period. This eliminates the risk of inclusion bias or referral bias. Other strengths are the centrally reviewed histology and complete follow-up with regard to survival. We intentionally excluded clinically diagnosed RCCs without histopathologic confirmation as these cases may have included benign kidney tumors and thus falsely improved the survival. It could also be argued that by excluding the clinically diagnosed cases, the RCC patients with the worst prognosis may have been omitted. However, including the clinically diagnosed patients from the multivariate analysis did not significantly change our main findings, neither for SM-rate or survival. A weakness of the study is the retrospective design, relatively small number of patients, with differences in the

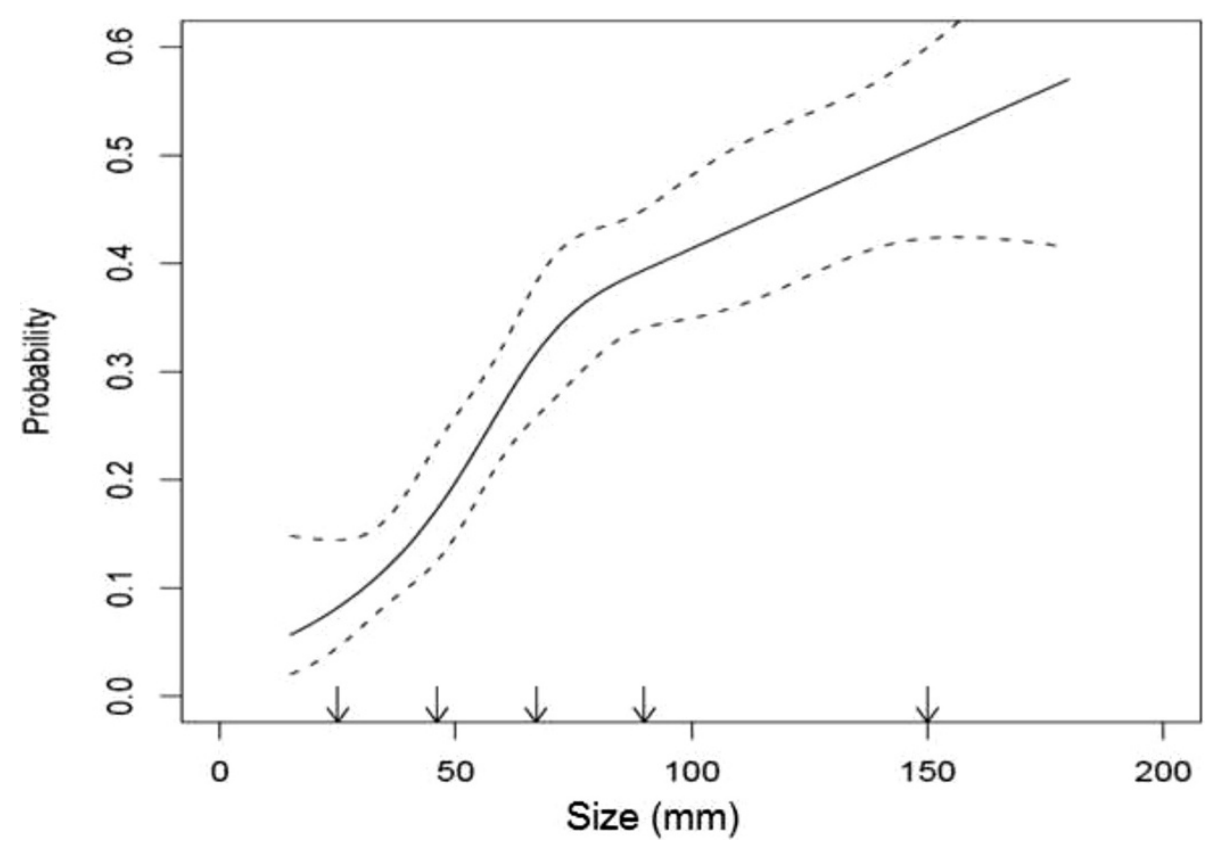

Figure 2 A cubic spline graph showing the relationship between tumour size and the probability of synchronous metastases in RCC patients dignosed in Iceland, 1971-2005. Dotted lines show 95\% Cl. 
Table 2 Comparison of clinicopathological factors for RCC patients diagnosed with and without synchronous metastases (SMs) in Iceland, 1971-2005

\begin{tabular}{|c|c|c|c|c|}
\hline & $\mathbf{N}$ & SM (\%) & $\begin{array}{l}\text { Without } \\
\text { SM (\%) }\end{array}$ & p-value* \\
\hline Mean age & 794 & $65( \pm 13)$ & $65( \pm 13)$ & 0.87 \\
\hline \multicolumn{5}{|l|}{ Gender } \\
\hline Male & 481 & $137(29)$ & $344(71)$ & 0.81 \\
\hline Female & 313 & $87(28)$ & $226(72)$ & \\
\hline Year of diagnosis & & & & $<0.001$ \\
\hline 1971-1975 & 65 & $23(35)$ & $45(65)$ & \\
\hline 1976-1980 & 65 & $22(36)$ & $41(64)$ & \\
\hline 1981-1985 & 92 & $36(39)$ & $56(61)$ & \\
\hline 1986-1990 & 103 & $40(38)$ & $64(62)$ & \\
\hline 1991-1995 & 127 & $32(25)$ & $95(75)$ & \\
\hline 1996-2000 & 139 & $25(18)$ & $114(82)$ & \\
\hline $2001-2005$ & 202 & $44(22)$ & $158(78)$ & \\
\hline Diagnosis & & & & $<0.001$ \\
\hline Incidental & 236 & $14(6)$ & $222(94)$ & \\
\hline Symptomatic & 558 & $207(37)$ & $351(63)$ & \\
\hline Laterality** & & & & $<0.001$ \\
\hline Right kidney & 427 & $94(22)$ & $333(78)$ & \\
\hline Left kidney & 359 & $122(34)$ & $237(66)$ & \\
\hline Mean ESR & & $29.7( \pm 32)$ & $59.1( \pm 39)$ & $<0.001$ \\
\hline Tumor size by category & & & & $<0.001$ \\
\hline $0.1-4.0$ & 177 & $19(11)$ & $158(89)$ & \\
\hline $4.1-7.0$ & 252 & $64(25)$ & $188(75)$ & \\
\hline $7.1-10.0$ & 226 & $80(35)$ & $146(65)$ & \\
\hline $10.1-13.0$ & 76 & $35(46)$ & $41(54)$ & \\
\hline $13.1-16.0$ & 46 & $24(53)$ & $22(47)$ & \\
\hline$>16.0$ & 17 & $10(61)$ & 7 (39) & \\
\hline T stage & & & & $<0.001$ \\
\hline T1a & 154 & $6(4)$ & $148(94)$ & \\
\hline $\mathrm{T} 1 \mathrm{~b}$ & 140 & $12(9)$ & $128(91)$ & \\
\hline $\mathrm{T} 2 \mathrm{a}$ & 92 & $16(17)$ & $76(82)$ & \\
\hline $\mathrm{T} 2 \mathrm{~b}$ & 51 & $14(36)$ & $37(64)$ & \\
\hline T3 & 328 & $125(38)$ & $203(62)$ & \\
\hline T4 & 30 & $11(63)$ & $19(47)$ & \\
\hline Histological RCC subtype & & & & 0.13 \\
\hline Clear cell & 705 & $194(28)$ & $511(72)$ & \\
\hline Papillary & 65 & $14(22)$ & $41(78)$ & \\
\hline Chromophobe & 15 & $1(7)$ & $14(93)$ & \\
\hline Other & 9 & $3(33)$ & $5(66)$ & \\
\hline Nuclear grade & & & & $<0.001$ \\
\hline | - || & 449 & $66(15)$ & $383(85)$ & \\
\hline III - IV & 345 & $147(43)$ & $198(57)$ & \\
\hline
\end{tabular}

*Mann-Whitney test for means, Chi-square test for trends. **Excluding 8 bilateral cases.Number of patients is given with percentage in parentheses, except for ESR and age where mean is given together with standard deviation.
Table 3 Multivariate analysis of the importance of size for the rate of synchronous metastases in patients diagnosed with RCC in Iceland, 1971-2005

\begin{tabular}{lccc}
\hline & Odds ratio & $\mathbf{9 5 \%} \mathbf{C l}$ & $\mathbf{p}$ \\
\hline Tumor size (per cm) & 1.09 & $1.04-1.16$ & 0.001 \\
Age & 1.00 & $0.98-1.01$ & 0.9 \\
Female gender & 0.87 & $0.57-1.30$ & 0.49 \\
Later diagnostic year (per decade) & 1.02 & $0.91-1.13$ & 0.94 \\
Incidental diagnosis & 0.22 & $0.11-0.41$ & $<0.001$ \\
ESR (each 1 mm/h) & 1.15 & $1.09-1.21$ & $<0.001$ \\
Left side & 1.67 & $1.12-2.50$ & 0.013 \\
Histology & & & \\
Clear cell & 1 & - & - \\
Chromophobe & 1.37 & $0-i n f i n i t y$ & 0.98 \\
Papillary & 0.93 & $0.42-2.03$ & 0.81 \\
Other/unknown & 1.27 & $0.11-14.71$ & 0.5 \\
\hline ESR and Size are continuous varibles. & & &
\end{tabular}

quality and quantity of staging and metastatic work-up over time, as well as changes in treatment options being offered. Further, in our study, average size is larger and incidental diagnosis less frequent than obtained in more contemporary series and may not reflect the more recent increase in incidentalomas.

The correlation between size and the probability of SM was strong in our data (Figures 1 and 2). Our findings are in line with the study by Kunkle et al. where tumour size independently predicted the odds of SM [9]. More recently, an almost linear relationship between size and SM for tumours $\leq 7 \mathrm{~cm}$ was described by Gudmundsson et al. in the NSKCR study [7]. In addition, based on the SEER database, Lugezzani et al. reported a similar relationship for T1 tumours, and Nguyen et al., found a sigmoidal relationship between size and SM that was comparable to the findings in the present study $[6,15]$.

The proportion of SM in the present study was higher than reported in other clinical studies, most of them contemporary series, with SM rates ranging between $0.1 \%$ and $7 \%[10,19-21]$. In population databases, the reported proportion of SM from the SEER database ranged from $3 \%$ to $6 \%$ and in the NSKCR study it was $7 \%$ $[6,7,15]$. This is similar to the SM-rate $(7 \%)$ found in our patients diagnosed after 1990. Unlike NSKCR, we did not evaluate the relationship between size, SM, and lymph node involvement, as lymph nodes were not systematically sampled or removed.

For tumors between 4.0 and $7.0 \mathrm{~cm}$, we found the relationship between size and SM rate to be virtually linear. This is in line with most previous studies $[6,9,15]$. For tumours larger than $7.0 \mathrm{~cm}$, earlier reports have shown that further increase in size adds less to metastatic potential $[6,15]$. While the shape of our cubic spline might 
Table 4 Multivariate analysis of the predictors for disease specific survival in patients diagnosed with RCC in Iceland, 1971-2005

\begin{tabular}{llll}
\hline & Hazard ratio & $\mathbf{9 5 \%} \mathbf{C l}$ & p-value \\
\hline Tumor size (cm) & 1.05 & $1.02-1.09$ & 0.01 \\
Later diagnostic year (by decades) & 0.90 & $0.85-0.95$ & 0.01 \\
Incidental detection & 0.74 & $0.52-1.03$ & 0.08 \\
Left sided tumour & 1.14 & $0.91-1.41$ & 0.24 \\
TNM group stage & & & \\
1 & 1 & - & - \\
2 & 2.34 & $1.36-3.99$ & $<0.001$ \\
3 & 3.54 & $2.21-5.71$ & $<0.001$ \\
4 & 13.16 & $8.14-21.28$ & $<0.001$ \\
Fuhrman nuclear grade & & & \\
1 & 1 & - & - \\
2 & 0.79 & $0.41-1.54$ & 0.49 \\
3 & 1.10 & $0.56-2.13$ & 0.78 \\
4 & 1.74 & $0.86-3.49$ & 0.12 \\
Histology & & & \\
Clear cell & 1 & - & - \\
Chromophobe & 0.13 & $0.01-0.97$ & 0.046 \\
Papillary & 0.88 & $0.52-1.46$ & 0.61 \\
Other/unknown & 1.61 & $0.39-6.64$ & 0.51 \\
\hline
\end{tabular}

suggest the same trend, the confidence interval also widens with increasing size, making it difficult to support such statements.

Despite the seemingly strong relationship between size and SM, it is noteworthy that the association is not statistically retained in a multivariate analysis after correcting for pT stage, grade, incidental detection, laterality, and other factors that were significant in the univariate analysis. At the same time, size clearly correlated with DSS in the Cox multivariate analysis. It has previously been shown in multivariate analyses not including stage, that size is a significant predictor of DSS, disease-free survival, and SM, with HR and OR of 1.2 or less [22,23]. Karakiewitz et al. included TNM stage in the multivariate analysis of 2,245 patients and found that knowing the exact size added $3.7 \%$ to the predictive accuracy for SM and only $0.8 \%$ to the predictive accuracy for DSS (2002 version) [24]. This, as well as the strong predictive value of of $\mathrm{pT}$ stage for SM and TNM stage for DSS in the present study, appears to confirm the value of the most recent (7th) version of the TNM-staging system.

\section{Conclusion}

We have shown in a nationwide cohort that tumour size correlates strongly with the rate of SM and is an
Table 5 Comparison of clinicopathological factors of patients with organ confined RCC without synchronous metastases who underwent nephrectomy by cause of death

\begin{tabular}{|c|c|c|c|c|}
\hline & $\mathbf{N}$ & $\begin{array}{l}\text { Death from } \\
\text { RCC (\%) }\end{array}$ & $\begin{array}{c}\text { Did not die } \\
\text { from RCC (\%) }\end{array}$ & p-value* \\
\hline Mean age & 370 & $62( \pm 13)$ & $62( \pm 12)$ & 0.62 \\
\hline \multicolumn{5}{|l|}{ Gender } \\
\hline Male & 227 & $41(18)$ & $186(82)$ & 0.67 \\
\hline Female & 143 & $23(16)$ & $120(84)$ & \\
\hline Year of diagnosis & & & & $<0.001$ \\
\hline 1971-1975 & 26 & $8(31)$ & $18(79)$ & \\
\hline 1976-1980 & 27 & $9(33)$ & $18(67)$ & \\
\hline 1981-1985 & 45 & $10(22)$ & $35(88)$ & \\
\hline 1986-1990 & 36 & $10(28)$ & $26(82)$ & \\
\hline 1991-1995 & 59 & $12(20)$ & $47(75)$ & \\
\hline 1996-2000 & 79 & $9(11)$ & $72(89)$ & \\
\hline 2001-2005 & 96 & $6(8)$ & $90(92)$ & \\
\hline Diagnosis & & & & $<0.001$ \\
\hline Incidental & 165 & $18(11)$ & $147(89)$ & \\
\hline Symptomatic & 205 & $46(22)$ & $159(78)$ & \\
\hline Laterality** & & & & 0.004 \\
\hline Right kidney & 205 & $28(14)$ & $177(86)$ & \\
\hline Left kidney & 165 & $36(22)$ & $129(78)$ & \\
\hline Mean ESR $(\mathrm{mm} / \mathrm{h})$ & & $21.0( \pm 24)$ & $38.8( \pm 40)$ & $<0.001$ \\
\hline T stage & & & & $<0.001$ \\
\hline T1a & 144 & $7(5)$ & $137(95)$ & \\
\hline T1b & 124 & $22(18)$ & $102(82)$ & \\
\hline T2a & 76 & $24(32)$ & $52(68)$ & \\
\hline $\mathrm{T} 2 \mathrm{~b}$ & 26 & $11(42)$ & $15(58)$ & \\
\hline Tumor size $(\mathrm{cm})$ & & $5.1( \pm 2.9)$ & $7.6( \pm 3.1)$ & $<0.001$ \\
\hline $\begin{array}{l}\text { Histological RCC } \\
\text { subtype }\end{array}$ & & & & 0.21 \\
\hline Clear cell & 315 & $56(18)$ & $256(82)$ & \\
\hline Papillary & 42 & $8(19)$ & $34(81)$ & \\
\hline Chromophobe & 11 & $0(0)$ & $11(100)$ & \\
\hline Other & 2 & $0(0)$ & $2(0)$ & \\
\hline Nuclear grade & & & & $<0.001$ \\
\hline | - || & 299 & $40(14)$ & $259(85)$ & \\
\hline III - IV & 71 & $24(34)$ & $47(66)$ & \\
\hline
\end{tabular}

Number of patients is given with percentage in parentheses, except for ESR and age where mean with standard deviation is given *Mann-Whitney test for means, Chi-square for trends.

independent prognostic factor of long-term survival after correcting for confounding variables. Tumor size therefore aids in prognostication, and is an addition to that predicted by the TNM-staging system, however, the difference is small. 


\section{Competing interests}

The authors declare they have no competing interests.

\section{Authors' contributions}

JPI and TG designed the study and wrote the manuscript. JPI, TG and GVE obtained infromation from charts $\mathrm{SH}$ and VP performed the pathological review, MIS performed the statistical analysis. EJ, GVE, SH, VP and MIS reviewed and edited the manuscript. All authors read and approved the final manuscript.

\section{Acknowledgements}

We thank Gunnhildur Johannsdottir for secretarial help and Eirikur Orri Gudmundsson MD for comments. This study was supported by a grant from the Landspitali University Hospital Scientific Foundation and the Memorial Foundation of Bergthora Magnusdottir and Jakob J. Bjarnason.

\section{Author details}

${ }^{1}$ Departments of Urology and Surgery, Memphis, Tennessee, USA.

${ }^{2}$ Pathology, Landspitali University Hospital, Reykjavik, Iceland. ${ }^{3}$ Faculty of Medicine, University of Iceland, Reykjavik, Iceland. ${ }^{4}$ Dartmouth-Hitchcock Medical Center, Lebanon, New Hampshire, USA.

Received: 1 December 2013 Accepted: 14 August 2014 Published: 31 August 2014

\section{References}

1. Gudbjartsson T, Thoroddsen A, Petursdottir V, Hardarson S, Magnusson J, Einarsson G: Effect of incidental detection for survival of patients with renal cell carcinoma: results of population-based study of 701 patients. Urol 2005, 66:1186-1191.

2. Ljungberg B, Cowan N, Hanbury D, Hora M, Kuczyk M, Sinescu I: EAU Guidlines on Renal Cell Carcinoma: The 2010 Update. Eur Urol 2010, 58:398-406.

3. Campbell S, Novick A, Belldegrun A, Blute M, Chow G, Uzzo R: Guideline for Management of the Clinical T1 Renal Mass. J Urol 2009, 182:1271-1279.

4. Schips L, Lipsky K, Ziegeuner R, Salfellner M, Winkler S, Humber G: Impact of tumor-associated symptoms on the prognosis of patients with renal cell carcinoma: a single-center experience of 683 patients. Urology 2003, 62:1024-1028.

5. Cheville J, Blute M, Zincke H, Lohse CM, Weaver A: Stage pT1 conventional (clear cell) renal cell carcinoma: pathological features associated with cancer specific survival. J Urol 2001, 166:453-456.

6. Lughezzani G, Jeldres C, Isbarn H, Perrotte P, Shariat S, Karakiewicz P: Tumor Size is a Determinant of the Rate of Stage T1 Renal Cell Cancer Synchronous Metastasis. J Urol 2009, 182:1287-1293.

7. Guðmundsson E, Hellborg H, Lundstam S, Erikson S, Ljungberg B: Metastatic Potential in Renal Cell Carcinomas $\leq 7 \mathrm{~cm}$ : Swedish Kidney Cancer Register Data. Eur Urol 2011, 60:975-982.

8. Kuczyk M, Wegener G, Merseburger AS, Anastasiadis A, Machtens S, Stenzl A: Impact of tumor size on the long term survival of patients with early stage renal cell cancer. World J Urol 2005, 23:50-54.

9. Kunkle D, Crispen P, Li T, Uzzo R: Tumor Size Predicts Synchronous Metastatic Renal Cell Carcinoma: Implications for Surveillance of Small Renal Masses. J Urol 2007, 177:1692-1697.

10. Klatte T, Patard J-J, De Martino M, Bensalah K, Verhoest A, Pantuck: Tumor Size Does Not Predict Risk of Metastatic Disease or Prognosis of Small Renal Cell Carcinomas. J Urol 2008, 179:1719-1726.

11. Klatte T, Patard J-J, Goel R, Kleid M, Guille F, Lam J: Prognostic impact of tumor size on pT2 renal cell carcinoma: an international multicenter experience. J Urol 2007, 178:35-40.

12. Ficarra V, Prayer-Galetti T, Novara G, Bratti E, Zanolla L: Tumor-size breakpoint for prognostic stratification of localized renal cell carcinoma. Urology 2004, 63:235-240.

13. Waalkes S, Becker F, Schrader A, Janssen M, Wegener G, Kuczyk M: Is There a Need to Further Subclassify pT2 Renal Cell Cancers as Implemented by the Revised 7th TNM Version? Eur Urol 2001, 59:258-263.

14. Brookman-May S, May M, Ziegeuner R, Shariat SF, Scherr DS, Pahernik S: Collecting System Invasion and Fuhrman Grade But Not Tumor Size Facilitate Prognostic Stratification of Patients With pT2 Renal cell Carcinoma. J Urol 2011, 186:2175-2181.
15. Nguyen M, Gill I: Effect of REnal Cancer Size on the Prevanlence of Metastasis at Diagnosis and Mortality. J Urol 2009, 181:1020-1027.

16. Kates M, Korets R, Sadeghi N, Pierorazio P, McKiernan J: Predictors of locally advanced and metastatic disease in patients with small renal masses. BJU Int 2012, 109:1463-1467.

17. Elbe J, Sauter G, Epstein J: World Health Organization International Classification of Tumours. Tumours of the Urinary Systmen and Male Genitla Organs. Lyons: IARC Press; 2004.

18. Greene F, Page D, Fleming ID: American Joint Committee on Cancer Staging Manual. New York: Springer-Verlag; 2002.

19. Pahernik S, Ziegler S, Roos F, Melchior S, Thuroff J: Small Renal Tumors: Correlation of Clinical and Pathological Features With Tumor Size. J Urol 2007, 178:414-147.

20. Thompson RH, Hill J, Babayev Y, Cronin A, Kaag M, Russo P: Metastatic Renal Cell Carcinoma Risk According to Size. J Urol 2009, 182:41-45.

21. Kume H, Suzuki M, Fujimura T, Fukuhara H, Enomoto Y, Homma Y: Distant Metastasis of Renal Cell Carcinoma With a Diameter of $3 \mathrm{~cm}$ or less - Which is Agressive Cancer. J Urol 2010, 184:64-68.

22. Yoo C, Song C, Hong JH, Kim C-S, Ahn H: Prognostic Significance of Perinephric Fat Infilitrtion and TUmor Size in Ranal Cell Carcinoma. J Urol 2008, 180:486-491.

23. Hutterer G, Patard J-J, Jeldres C, Perrotte P, De La Taille A, Karakiewicz P: Patients with distant metastase from renal cell carcinoma can be accurately identified: external validation of a new nomogram. BJU Int 2008, 101:39-43.

24. Karakiewicz P, Lewinstein D, Chun F, Briganti A, Guille F, Patard J-J: Tumor Size Improves the Accuracy of TNM Predictions in Patients with Renal Cancer. Eur Urol 2006, 50:521-529.

doi:10.1186/1471-2490-14-72

Cite this article as: Ingimarsson et al:: The impact of tumour size on the probability of synchronous metastasis and survival in renal cell carcinoma patients: a population-based study. BMC Urology 2014 14:72.

\section{Submit your next manuscript to BioMed Central and take full advantage of:}

- Convenient online submission

- Thorough peer review

- No space constraints or color figure charges

- Immediate publication on acceptance

- Inclusion in PubMed, CAS, Scopus and Google Scholar

- Research which is freely available for redistribution

Submit your manuscript at www.biomedcentral.com/submit
C Biomed Central 